\title{
The Effect Of Cultural Values, Professional Engineering Cultures, And Technology On International Joint Ventures In Mexico And The United States
}

Robert Nieves, (Email: RobertNieves@ adelphia.net), Nova Southeastern University Bahaudin G. Mujtaba, (Email: Mujtaba@ sbe.nova.edu), Nova Southeastern University

\begin{abstract}
Recent economic developments and changes in international trade relations are increasing the number of international joint ventures that are managed by professional engineers. This trend has created a need for a greater understanding of the interaction and effect of values, culture, and technology in a multicultural environment on the likelihood of success and the performance of international joint ventures. This study discusses the cultural values, professional engineering cultures, and the effect of technology on the values of engineering managers and subordinates and how these factors affect the formation, structure, and outcomes of international joint ventures in Mexico and the United States. Furthermore, the results of this study are obtained from the Hofstede's Value Module Survey and the Schwartz's Value Survey to distinguish between the Mexican and United States' cultures.
\end{abstract}

\section{CULTURAL VALUES}

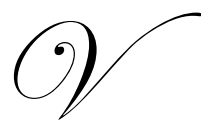

alues serve as a link between the engineer and the organization. An engineer or an individual relates to the group while still maintaining his or her own identity. Values represent psychological, biological, and social needs of the individual. This representation is the result of the relationship between attitudes, behavior, and values. Values impact a multitude of disciplines, such as, anthropology, business, psychology, sociology, and even technology. Values serve as the roles of constructs in social processes, and as a research interest in cultural, educational, political, and work-related studies. Values play a key role in organizations since people assess situations and make decision at work using values as their criteria.

Hofstede (1980, 1983, and 1984) considers values to be central to cultural differences between technical managers. Managers from different cultures are expected to differ in the importance of personal values. Values influence behavior, so these differences in personal values are reflected in their managerial behavior. According to Dunning (1997), firms which are best to identify and reconcile cultural differences, or even exploit them to their gain, are likely to acquire a noticeable competitive advantage in the marketplace. The fit between cultural values and management practices is reinforced when management understands the values of the people with whom they are doing business, and this fit is important in building an excellent and lasting working relationship between the engineering manager and its subordinates, or between employees and customers.

The lack of understanding in an organization of managerial attitudes, work values, and behaviors, could result in the failure of the business venture. Managers from different cultures could interpret information differently. A breakdown in communication between managers involved in international business could be very costly to the firm.

The awareness of what values influence attitudes and behavior helps identify cultural differences and the reasons behind them, as well as recognizing ways to lessen these cultural differences between individuals and 
organizations. The interaction between Mexican and United States engineers is an ideal setting to understand the convergence or divergence of values across cultures. This professional interaction will continue to grow with NAFTA in the foreseeable future, and will highlight the importance of this research to international management.

The study of human values has become increasingly important to researchers trying to understand and measure the impact that changing values have on behavior, cultures, and organizations of human beings. Today's international firms have engineers with different cultural backgrounds and value systems all over the world. These firms are trying to better understand engineers' attitudes and practices to improve the performance of the international organizations and the effectiveness of their management.

International firms and engineers would benefit from a better understanding of the relationship between values of the engineer and the corporate culture. Corporate culture is defined by the values of corporate managers and their subordinates. A strong corporate culture is possible when if the employees' values are in agreement with those of the firm.

Culture has to do with the way people live and behave in a social and organizational setting. Hofstede (1994) defines culture as "the collective programming of the mind which distinguishes the members of one group or category of people from another." He observed that collective mental programming, although not directly observable is shared within, but between groups of people, and that managerial groups shared this collective programming. He found profound differences in the attitudes and behavior of managers and subordinates across cultures.

According to Adler (1991), culture is the result of a complex interaction of values, attitudes, and behaviors of the individuals in a group. Values influence attitudes; attitudes affect behavior, and behavior impacts culture. Values, attitudes, and behavior reinforce one another and adjust in a circular way. Values are beliefs that describe an individual's preferences and alternatives between appropriate and inappropriate behaviors. Values are recognized as the foundation of culture. An understanding of values is critical to understand behavior.

The differences between cultures, social classes, professions, religions, and political affiliations could be reflected by an individual's answers to "values" questions, reinforcing that "values" research is effective across different cultural environments. An individual's values can be used to make cross-cultural assessments in international studies (Schwartz, 1987, 1992, 1999).

Societies and individuals could be compared to other societies and individuals on the basis of their values. There are instruments of "values" measurement, such as, Hoftede's (1980) Value Model, and Schwartz's (1996) Value Model, that would be useful in a study of values across different cultures. Each model or survey has shown that personal values influence behavior, beliefs, attitudes, and preferences in a wide range of situations. The Schwartz's and Hofstede's Value Models have been used by the authors in a study of engineers from Mexico and the United States to assess the impact of technology and its level of economic development on cultural values within organizations.

\section{PROFESSIONAL ENGINEERING CULTURES}

The professional cultures of engineers represent such a variety of norms, beliefs, and priorities, they can create communication problems and group conflict. The professional engineering culture is a type of culture that can affect international joint ventures, but has not received the same amount of attention from researchers than the general organizational culture. A Professional Engineers Culture evolves when a group of engineers who are employed in a functionally similar occupation share a set of beliefs, norms, and values related to that occupation. The Professional Engineering Culture develops through the socialization that engineers are involved with during their occupational training and education.

Engineers' professional experiences and interactions serve to reinforce their socialization process and convey a more profound understanding of how the engineering occupation should be conducted. The socialization process that engineers undergo in this manner is very strong and permeates their professional culture. The engineering 
occupation becomes highly organized, distinct and pervasive within engineering organizational culture. Members of a professional engineering culture share a kind of mindset that not only encompasses the emotional or social aspects of the occupation, but also provides pragmatic functional understanding of the occupational field. Thus, most professional engineering fields in an organization, electrical, mechanical, civil, chemical, software, and others, have distinct professional engineering cultures. Within these professional engineering cultures there are engineering subcultures.

Professional Engineering Subcultures develop within an organization and are the product of shared and valued experiences, such as educational, personal background, similar challenges, or occupational field. An engineering subculture is a solution to a group's need to belong to a larger membership, while also possessing some level of independence from that group membership. Professional Engineering Cultures cut across organizational boundaries. For instance, international joint ventures are a prime example of how pervasive a professional engineering culture may become across the organizational boundary. An international joint venture may require its engineers to interface in the value-adding activity of the venture regardless of the engineers' professional cultures. These engineers may have very distinctive professional cultures and occupational socialization and may not typically have an operational common ground.

Engineers from distinct professional cultures may lack a shared set of experiences and values and their socialization may have a different context. Their different professional experiences have reinforced a distinct context in their occupational socialization. These engineers may not be experienced in communicating with another professional engineering culture outside of their own. Therefore, the communication process between engineers from different professional engineering cultures may fail. Under this scenario, the international joint venture needs to direct resources and time from its value-adding activity to developing a process that builds a shared set of experiences, values, and understanding, in order to improve communication and cohesiveness among the different professional engineering cultures. The lack of this process development will result in bigger losses to the joint venture because of the expense and time required to establish the necessary improvement.

The required developmental process needs to take into consideration the problem solving preferences of engineers from different professional cultures since resistance to change the old ways may be difficult to overcome as engineers may try to stick to the old approach that has always worked in their professional engineering culture. It is in the unification and merge of the engineers' shared set of experiences and values that a pragmatic and acceptable solution will be found. The international joint venture will then benefit from the combined expertise of all professional engineering cultures involved in the venture.

Moreover, engineers in the international joint venture must be able to interface effectively across their professional engineering cultural boundaries in order to share, combine, and leverage their expertise and resources to contribute to the value-adding activity and success of the venture. Thus, values, cultures, attitudes, and behavior affect the interactions of engineers and are critical in understanding international joint venture outcomes.

Furthermore, an international joint venture is an increasingly important investment for expanding a company's competitive advantage in the global marketplace. These ventures face tough challenges from distinct sources of professional engineering cultures. Effective communication and cooperation depend on identifying and removing the most unproductive aspects of cultural differences among the engineering members of the professional cultures involved in the venture. Thus, in this manner, international joint ventures raise the probability that their combined engineering resources will be shared and leveraged in the value-adding activity of the venture, leading to better performance.

\section{RESEARCH METHODOLOGY}

The research methodology calls for conducting surveys in Mexico and the United States, with at least 20-50 engineers that work for companies that manufacture, distribute, or service electrical equipment. Performing an independent sample t-test and a t-test for the quality of means of the difference in sample means between the Mexican and the U.S. samples will test hypotheses $\mathrm{H} 1, \mathrm{H} 2, \mathrm{H} 3$, and $\mathrm{H} 4$ for power distance, individualism / collectivism, 
masculinity/femininity, and uncertainty avoidance, and the result is compared to Hofstede's IBM study to assess statistical significance between two sample means in order to determine if there is a reduction in the difference, and that the difference is real, and it is not due to chance or sample variation.

Chi-square tests are performed on the cross-tabulation of the Mexican and the U.S. samples using the engineering degree level (Bachelor, Master, $\mathrm{PhD}$ ), Hofstede's cultural dimension scores, and individual demographic variables such as: age, gender, and occupation, to determine any statistically significant relationships between the variables, and the impact of the independent demographic variables on the cultural dimensions.

An independent sample t-test and a t-test for the quality of the means is performed on the cross-tabulation of the Mexican and the US samples using the engineering degree level (Bachelor, Master, $\mathrm{PhD}$.) and cultural dimension scores for power distance, individualism / collectivism, masculinity/femininity, and uncertainty avoidance, to control for this specific variable, to determine its individual impact in the difference between cultural dimension scores for each sample, and to confirm the Chi-square tests results. A correlation test is performed on hypothesis H5 across the Mexican and the US samples between scores on Hofstede's cultural dimensions and Schwartz's culture-level dimensions, which are theoretically linked. This correlation test measures the linear association between Hofstede's and Schwartz's dimensions.

This study uses a comparative research design because it seeks to compare the cultural scores for engineers in Mexico and the United States to identify whether the level of technology and its corresponding level of development influence cultural convergence. The influence of level of technology on cultural convergence was determined as follows:

- $\quad$ Measuring Schwartz's culture-level value dimensions for engineers in Mexico and the United States, and correlating their scores to Hofstede's cultural dimensions in order to validate the linear relationship between both dimensional results.

- Measuring Hofstede's cultural dimensions (power distance, individualism/collectivism, masculinity/femininity, and uncertainty avoidance) for two sample populations of engineers in Mexico and the United States, in order to statistically compare the resultant scores to Hofstede's IBM study scores, to identify if a reduction in cultural differences between the two samples of engineers has taken place.

- $\quad$ Measuring Hofstede's scores for cultural dimensions and statistically examining the scores by individual demographic variables such as: age, gender, occupation, engineering degree level, and cultural dimensions, across both samples, to obtain the impact of the demographic variables on the cultural dimensions, and to determine any statistically significant relationships between these variables.

Research data was collected by conducting surveys in Mexico and the United States, with a minimum of 20 engineers that work for companies that manufacture, distribute, or service electrical equipment, using two questionnaires: the Schwartz Value Survey (SVS) and Hofstede's VSM 94. The study began with a sample of Mexican and United States companies. These companies are part of a global manufacturing and distribution network for major multinational companies.

The sample is expected to be well-matched with regards to engineering education, gender, age, and occupation. In this study, the goal is to obtain 20 to 50 well-matched engineers per country, even though, Hofstede recommended a minimum of 20 respondents per country to remove individual influences and assure statistical significance (VSM 94 Manual). The sampling procedure was conducted via regular mail and electronic mail. Each questionnaire included a cover letter, which described the nature of the research study, the importance of participating in the study, and the reason why engineers were selected for the study. Only respondents who are citizens of Mexico or the United States and had an engineering degree were asked to take the survey to avoid erroneous results and conclusions. 
The surveys were conducted in Mexico and the United States, a developing country and a developed country. The choice of countries allowed for cultural diversity and minimized language barriers, with the validated surveys available in English and Spanish from the key researchers in the field. Small and medium-sized companies and professional engineering societies were targeted; the small companies are distributors of electrical equipment and machinery that design, sell, service, or rent products, or electrical and civil engineering consultants and the medium companies are manufacturers of electrical equipment and machinery sold by distributors.

The research population consisted of sales engineers, design engineers, service engineers, and managers who are in very technical positions at various levels of the organization. The majority of these engineers have an electrical engineering, mechanical engineering, civil engineering, or software engineering background. Their educational studies at the university have consisted of two years of general education courses in English or Spanish composition, social science, physics, chemistry, humanities, and mathematics, and the last two years of college studies for their career have been concentrated on their specialty or engineering field. The combined population of Mexican engineers in the Mexican companies was 37. The combined population of United States engineers in the American companies was 47. All respondents were asked to participate willingly and voluntarily in the study.

\section{Research Question}

The research question asks: to what extent do the level of technology and its corresponding level of development play a role in lessening cultural differences between engineers in Mexico and the United States. A comparative analysis of engineers' cultural values was conducted on two samples of engineers in Mexico and the United States, in the electrical equipment business of the energy market. Technology and its corresponding level of development is a force that may be working toward cultural convergence by helping to narrow cultural differences; technology is becoming more uniform across countries, and thus may be promoting more uniform cultural values.

H1: The difference in power distance scores between engineers in Mexico and the U.S. will be less than the differences found in the Hofstede's IBM study.

H2: The difference in individualism scores between engineers in Mexico and the U.S. will be less than the differences found in the Hofstede's IBM study.

H3: The difference in masculinity scores between engineers in Mexico and the U.S. will be less than the differences found in the Hofstede's IBM study.

H4: The difference in uncertainty avoidance scores between engineers in Mexico and the U.S. will be less than the differences found in the Hofstede's IBM study.

H5: For the Mexico and the U.S. engineer samples, the scores on Hofstede's cultural dimensions will show significant correlation with the scores on Schwartz's culture-level dimensions.

\section{Technology and Cultural Values of Engineering Managers}

The study conducted by the authors compares the cultural values of engineering managers and subordinates in Mexico and the United States. The study aims to assess the impact of technology on lessening cultural differences between engineers in a multicultural environment, such as an international joint venture and its relationship to the success or failure of the business alliance.

Table 1.1: Occupation Frequency Distribution By Country

\begin{tabular}{|c|c|c|c|c|}
\hline Occupation & Mexico & Percent & United States & Percent \\
\hline Manager & 21 & 56.76 & 31 & 65.96 \\
\hline Non-Manager & 16 & 43.24 & 16 & 34.04 \\
\hline Not Defined & 0 & 0 & 0 & 0 \\
\hline Total & 37 & 100.00 & 47 & 100.00 \\
\hline
\end{tabular}


Five hypotheses were proposed and tested using independent sample t-tests, t-tests for the quality of means, Chi-square tests on the cross-tabulation of independent demographic variables, and a correlation test on hypothesis $\mathrm{H} 5$ between scores on Hofstede's cultural dimensions and Schwartz's culture-level dimensions.

Table 1.2: The Results For The Five Hypotheses Tested

\begin{tabular}{|c|c|}
\hline Hypotheses & Findings \\
\hline $\begin{array}{l}\text { H1: The difference in power distance scores between engineers in Mexico and the United States will } \\
\text { be less than the differences found in the Hofstede's IBM study. }\end{array}$ & Supported \\
\hline $\begin{array}{l}\text { H2: The difference in individualism scores between engineers in Mexico and the United States will be } \\
\text { less than the differences found in the Hofstede's IBM study. }\end{array}$ & Not Supported \\
\hline $\begin{array}{l}\text { H3: The difference in masculinity scores between engineers in Mexico and the United States will be } \\
\text { less than the differences found in the Hofstede's IBM study. }\end{array}$ & Supported \\
\hline $\begin{array}{l}\text { H4: The difference in uncertainty avoidance scores between engineers in Mexico and the United } \\
\text { States will be less than the differences found in the Hofstede's IBM study. }\end{array}$ & Supported \\
\hline $\begin{array}{l}\text { H5: For the Mexico and the United States engineer samples, the scores on Hofstede's cultural } \\
\text { dimensions will show significant correlation with the scores on Schwartz's culture-level } \\
\text { dimensions. }\end{array}$ & $\begin{array}{c}\text { Partially } \\
\text { Supported }\end{array}$ \\
\hline
\end{tabular}

This study has found that technology does play a significant role in reducing the cultural differences between two engineer samples. Other key demographic variables were not found to play a significant role. Thus, national culture does not represent the strongest and only force driving individual work values towards divergence. Technology and its corresponding level of development is a significant force acting on the convergence-divergence dimension of cultural values. The study also found a correlation between Schwartz's culture-level dimensions and Hofstede's cultural dimensions.

This study and its results add to the existing knowledge of cultural convergence or divergence. First, the study provides a strong indication that there is factual evidence of cultural convergence between the Mexican engineer sample and the United States sample, and that cultural differences are lessening with respect to Individualism, Power Distance, and Uncertainty Avoidance, but not in Masculinity.

In the Masculinity dimension, there is evidence of divergence, as noted by the statistically mean difference for Masculinity between the samples. Second, the results indicate that contrary to Hofstede's (1997) assertions that the four cultural dimensions are resilient and stable, as a country's score changes over time, the scores do not necessary remain unchanged when compared to the scores of another country. Moreover, the lessening of the cultural differences found in this study challenge Hofstede's concept that technological advancement, economic structure, international trade, and the passage of time itself, would play a more significant and lasting role than Hofstede originally anticipated on the four cultural dimensions.

Third, the lack of statistically significant relationships between Individualism, Power Distance, Masculinity, and Uncertainty Avoidance and the demographic variables, such as age, gender, engineering degree level, and occupation support that the concept of nation influences Hofstede's cultural dimensions more than the demographic variables examined in this study.

The results of this study confirmed that Hofstede's and Schwartz's cultural dimensions are conceptually linked and both provide a conceptual system to explain and test the concept of national culture and its effect on cultural values.

Fourth, this study contributes to Mexican and United States International Joint Ventures by providing a cultural profile for engineers doing business in each other's countries or in situations where the international joint venture is considering placing a Mexican or United States engineer in a management position across the cultural border. This cultural profile may be useful to avoid difficulties when selecting an engineer for an international assignment and in the implementation of management strategies such as, personnel organization and management, planning, and administration. 
Table 1.3: Correlation Between Schwartz's And Hofstede's: Mexico \& US

\begin{tabular}{|c|c|c|c|c|}
\hline \multicolumn{5}{|c|}{ Hofstede's Cultural Dimensions } \\
\hline $\begin{array}{c}\text { Schwartz' } \\
\text { Cultural Dimensions } \\
\end{array}$ & Individualism & Masculinity & $\begin{array}{c}\text { Power } \\
\text { Distance }\end{array}$ & $\begin{array}{c}\text { Uncertainty } \\
\text { Avoidance } \\
\end{array}$ \\
\hline $\begin{array}{c}\text { Affective Autonomy } \\
\text { Pearson Correlation } \\
\text { Sig.(1-tailed) } \\
\text { N }\end{array}$ & $\begin{array}{c}.338 * * \\
.001 \\
84\end{array}$ & $\begin{array}{c}.120 \\
.139 \\
84\end{array}$ & $\begin{array}{c}-.083 \\
.227 \\
84\end{array}$ & $\begin{array}{c}.102 \\
.177 \\
84\end{array}$ \\
\hline $\begin{array}{c}\text { Intellectual Autonomy } \\
\text { Pearson Correlation } \\
\text { Sig.(1-tailed) } \\
\text { N }\end{array}$ & $\begin{array}{c}.004 \\
.487 \\
84 \\
\end{array}$ & $\begin{array}{c}-.031 \\
.388 \\
84 \\
\end{array}$ & $\begin{array}{c}-.078 \\
.239 \\
84 \\
\end{array}$ & $\begin{array}{c}-.065 \\
.279 \\
84 \\
\end{array}$ \\
\hline $\begin{array}{c}\text { Egalitarianism } \\
\text { Pearson Correlation } \\
\text { Sig.(1-tailed) } \\
\mathrm{N} \\
\end{array}$ & $\begin{array}{c}-.075 \\
.248 \\
84 \\
\end{array}$ & $\begin{array}{c}-.155 \\
.080 \\
84 \\
\end{array}$ & $\begin{array}{c}-.122 \\
.135 \\
84 \\
\end{array}$ & $\begin{array}{c}-.041 \\
.356 \\
84 \\
\end{array}$ \\
\hline $\begin{array}{c}\text { Embeddedness } \\
\text { Pearson Correlation } \\
\text { Sig.(1-tailed) } \\
\mathrm{N} \\
\end{array}$ & $\begin{array}{c}-.087 \\
.215 \\
84 \\
\end{array}$ & $\begin{array}{c}-.043 \\
.349 \\
84 \\
\end{array}$ & $\begin{array}{c}.119 \\
.141 \\
84 \\
\end{array}$ & $\begin{array}{c}.025 \\
.411 \\
84 \\
\end{array}$ \\
\hline $\begin{array}{c}\text { Harmony } \\
\text { Pearson Correlation } \\
\text { Sig.(1-tailed) } \\
\text { N }\end{array}$ & $\begin{array}{c}.019 \\
.432 \\
84\end{array}$ & $\begin{array}{l}.092 \\
.203 \\
84\end{array}$ & $\begin{array}{l}.068 \\
.268 \\
84\end{array}$ & $\begin{array}{l}.063 \\
.283 \\
84\end{array}$ \\
\hline $\begin{array}{c}\text { Hierarchy } \\
\text { Pearson Correlation } \\
\text { Sig.(1-tailed) } \\
\text { N }\end{array}$ & $\begin{array}{c}.103 \\
.176 \\
84\end{array}$ & $\begin{array}{l}.034 \\
.378 \\
84\end{array}$ & $\begin{array}{c}-.243 * \\
.013 \\
84\end{array}$ & $\begin{array}{l}.036 \\
.372 \\
84\end{array}$ \\
\hline $\begin{array}{r}\text { Mastery } \\
\text { Pearson Correlation } \\
\text { Sig.(1-tailed) } \\
\mathrm{N}\end{array}$ & $\begin{array}{l}.047 \\
.336 \\
84\end{array}$ & $\begin{array}{c}.111 \\
.156 \\
84\end{array}$ & $\begin{array}{c}-.126 \\
.128 \\
84\end{array}$ & $\begin{array}{c}.012 \\
.458 \\
84\end{array}$ \\
\hline
\end{tabular}

* Correlation is significant at the 0.05 level (1-tailed).

** Correlation is significant at the 0.01 level (1-tailed).

Table 1.4- Hofstede's Scores for Mexico and the US - Present Study

\begin{tabular}{|c|c|c|}
\hline Cultural Dimension & Mexico & United States \\
\hline Individualism & 66.49 & 89.15 \\
\hline Masculinity & 67.03 & 37.87 \\
\hline Power Distance & 38.51 & 34.26 \\
\hline Uncertainty Avoidance & 52.43 & 63.51 \\
\hline
\end{tabular}

This research has led to some interesting findings and has also opened the door of future research into other potential areas for the study of values of international engineering managers and their organizations. The Hofstede's dimension of long-term orientation was not specifically addressed in this study. Perhaps this dimension, which seems to be so different between cultures when comparing United States values to a country like China, would provide ample research for future studies. Also, each of the dimensions of the Schwartz's model would provide areas for future research to determine convergence or divergence over time. Moreover, each of the dimensions that make up Schwartz's cultural dimensions may be deeper and broader than this study was able to measure. 
Table 1.5: Schwartz's Scores for Mexico and the US - Present Study

\begin{tabular}{|c|c|c|}
\hline Culture-Level Value Type & $\begin{array}{c}\text { Mexico } \\
\mathbf{N = 3 7}\end{array}$ & $\begin{array}{c}\text { United States } \\
\mathbf{N}=\mathbf{4 7}\end{array}$ \\
\hline Affective Autonomy & 3.58 & 3.95 \\
\hline Intellectual Autonomy & 4.38 & 4.42 \\
\hline Egalitarianism & 4.77 & 4.64 \\
\hline Embeddedness & 3.99 & 3.74 \\
\hline Harmony & 3.53 & 3.50 \\
\hline Hierarchy & 2.67 & 2.82 \\
\hline Mastery & 4.31 & 4.16 \\
\hline
\end{tabular}

Future studies should be considered to determine between the convergence-divergence of values and the success and performance of international joint ventures. It should be interesting if past values have an effect on work performance with the passage of time. The difference in values between the engineer populations in two different countries might be studied with engineer value convergence compared to performance. If a relationship is found to exist, then it might be possible to closely match an engineer's value profile to the values of an organization at a different location. The possibility and feasibility of relocating engineering managers might then be researched for effective performance.

The impact of technology on individual human values is so pervasive, that we are apt not to notice it. Technology is impossible to pin down either in precise meaning or at a particular point, because it is dynamic. Technology has always had an impact on individual human values, as the various technologies for design, production, and communication have changed over time. There are plenty of examples of a new technology having major effects on cultural values, such as the invention of the automobile, computer, and communication devices.

It is not a question of either technology or individual human values having an overriding influence on the other; they continually interact. Technology is a permanent dynamic force that interacts with our human value system. This has a crucial effect on cultural values, organizations, and engineers.

Technology is affecting the way we think and the way we perceive the world. Technology has an impact on the sense of self. The impact of technology on individual human values will profoundly affect the way we behave and think, and thus will have a wider cultural influence as the pace and breath of technological changes grow in the future.

In this study, no statistical significance was found between the Engineering Degree Level and Individualism, Masculinity, Power Distance, and Uncertainty Avoidance. There was also a lack of statistical significance on the individual demographic variables, such as, age, gender, and occupation. Chi-square tests resulted in no statistical significance at the 95 percent confidence level for the relationships between the variables, and the impact of the independent demographic variables on the cultural dimensions. Moreover, the results of the independent sample t-tests confirmed the lack of statistically significant relationships between the individual demographic variables and Hofstede's cultural dimensions.

The fact that there are no statistically significant relationships between Hofstede's cultural dimensions and individual demographic variables is explained by Schwartz's (1995) findings that the country variable helps explain three times the variance when compared to other individual demographic variables (Schwartz, 1990, 2000).

It is also worth mentioning that the engineer samples in this study for the Bachelor, Master, and Ph.D. engineering degree levels are small, so caution should be used when drawing further conclusions. For instance, there were 28 engineers holding a Bachelor in the Mexican engineer sample versus 27 in the United States engineer sample, 9 engineers holding a Master in the Mexican engineer sample versus 9 in the United States engineer sample, and 11 engineers holding a Ph.D. in the United States engineer sample, but none in the Mexican engineer sample. Furthermore, there is also the possibility that the extent and veracity of the impact of the Engineering Degree Level is not fully represented by the Hofstede's questionnaire and its cultural dimensions. 
Table 1.6: Engineering Degree Level Frequency Distribution By Country

\begin{tabular}{|c|c|c|c|c|}
\hline Engineering degree Level & Mexico & Percent & United States & Percent \\
\hline Bachelor & 28 & 75.68 & 27 & 57.45 \\
\hline Master & 9 & 24.32 & 9 & 19.15 \\
\hline Ph.D. & 0 & 0 & 11 & 23.40 \\
\hline Not Defined & 0 & 0 & 0 & 0 \\
\hline Total & 37 & 100.00 & 47 & 100.00 \\
\hline
\end{tabular}

\section{THE SUCCESS OR FAILURE OF INTERNATIONAL JOINT VENTURES}

Recent global economic growth and the passage of both NAFTA and CAFTA are promising an increasing number of firms to enter international joint ventures. A key factor in determining the success or failure of international joint ventures is the combined engineering resources of the firms in the venture to manage, communicate effectively, and perform critical engineering functions in the value-adding activities of the venture.

The performance of the international joint venture is largely affected by the ability of its engineering managers and subordinates to manage in a multicultural environment. The considerable failure rate and intricacy of the cultural environment in an international joint venture evokes that an assessment of the management practices, cultural values, and the level of technology and its effect on cultural values, is necessary.

Oftentimes, engineering managers assume that their management practices in their home country will be equally effective in other countries, only to find that managers and subordinates abroad have different cultural values and communication styles and, hence, do not have the expected results to those management practices. For example, engineering managers involved in Mexico-United States joint ventures can therefore benefit from learning how cultural values and communication in Mexico and the United States differ and the implications of those differences for management practices and joint venture performance in each country.

Prevalent comparative studies of Mexican and United States' individual values have concentrated on national culture rather than values specifically pertaining to engineering managers and subordinates and even less on the impact of the level of technology on the cultural values of engineers. Thus, comparative assessment of cultural values and the impact of the level of technology on those values become beneficial to firms entering international joint ventures and provide engineering managers with a cultivated understanding of the differences among their subordinates in Mexico and the United States. The analysis of this comparative assessment will allow engineering managers to make predictions about the effectiveness of their management practices in each country or within the multicultural environment. For instance, cultural differences such as the prevalence of collectivism in Mexican engineering managers and individualism in the United States engineering managers has an impact on their management practices and communication styles. Thus, these practices would impact the joint venture outcome and reflect the engineering managers' cultural values.

The performance of the international joint venture will be determined by the cohesive management practices and the structure of the venture. The compatibility of the joint venture management practices between the Mexican company and the United States company would provide a more meaningful explanation of the lifespan and failure of international joint ventures than any apparent similarity in cultural values between the engineering managers of the firms. Generally, a lack of congruence among various work values, such as, power distance, individualism, collectivism, and uncertainty avoidance, may create resistance to change and conflict in international joint ventures. The development of joint venture management practices by the venture managers and a value-adding functional structure will contribute to the success of the international joint venture.

The role of the engineering managers is critical in the success of the joint venture and their ability to motivate, change the organizational processes and converge problem-solving attitudes and expertise into a common framework needs to be innate to their leadership qualities. As management leaders, these managers persuade other organizational members to accomplish recommended changes inferred by the management team and are consequential to the good performance of the joint venture. 
Notwithstanding the key role that management plays in international joint ventures, more research is needed to examine the management of international joint ventures, manager's cultural values and orientations, and the effect they have on the success of the joint venture.

Managerial capabilities must be emphasized in multicultural environments to determine a good fit between venture partners. The effective management practices of congruent engineering cultures will allow joint ventures to perform better. In the case of Mexico-United States joint ventures, ventures continue to grow significantly. A joint study by the Mexican Center of Economic Studies in the Private Sector and the Conference Board of New York reported that 80 percent of Mexican investors regard international joint ventures as a significant business strategy to reach emerging markets. Mexico is and will be for the foreseeable future a strategic business ally for the United States; and it is a fact that most foreign direct investment in Mexico comes from the United States. According to the Mexican Secretaria de Economia (SDE, 2005), United States investments accounted for 62.6 percent of all foreign direct investment in Mexico, with a total investment of \$90,030 Million from 1994 to 2004, and was attributable to more than 2,600 United States companies with business ventures in Mexico (INEGI, 2004).

The Mexico-United States business relationship invites engineering managers to combine their experiences, expertise, and actions with their business partners' to achieve a greater effect on the performance and market positioning of the joint venture. Engineering Managers working in multicultural environments are prone to emphasize individual aspects of the joint venture business and contribute different factors into the prevalent management practices of the venture.

The initial business relationship of Mexican and United States engineering managers would naturally progress from a strategic assessment of economic factors of the venture towards a more personal and social relationship. As these business and personal relationships develop international joint venture managers are expected to develop other managerial capabilities and practices that would further reduce operating costs and improve the

likelihood of success of the joint venture. The lack of engineering management attention during the initial process of formation of the international joint venture and the implementation of a structure that provides the framework to unite the engineering culture that are part of the value-adding business activity may undermine the creation of successful business and personal relationships and the establishment of the effective problem-solving mechanism that would resolve the conflicts that are expected in an international joint venture.

Engineering managers need to share a professional managerial culture through the processes of complex social and cultural negotiation in multicultural organizations, such as, international joint ventures to blend the cultural values and expertise of managers into a cohesive and prevalent management style.

\section{CONCLUSION}

International joint ventures are an increasingly important tool for expanding a firm's competitive advantage. These joint ventures and their engineering managers face challenges from several sources of cultural value difference; effective communication and collaboration depend on shaping a productive professional engineering culture. In this way, international joint venture firms increase the likelihood that their combined expertise and engineering resources will be leveraged in the value-adding activity of the joint venture, leading to better performance.

Engineering managers in international joint ventures face the challenge of alignment between the organizational structure and unifying professional engineering culture and their individual cultural values. This study has shown that international joint ventures in particular are influenced by cultural values, professional engineering cultures, and technology, and that these factors can be measured in the case of Mexican versus United States culture on the "value" dimensions from Hofstede's and Schwartz's Value Models. Furthermore, this study indicates that international joint ventures are highly influenced by the professional engineering cultures of the firms involved. Engineering managers should understand that the organizational structure of the international joint venture should be adjusted to fit the combined professional engineering culture, since cultural values are more complex and much more difficult to change. 


\section{REFERENCES}

1. Adler, Nancy J. (1991). International dimensions of organizational behavior. $2^{\text {nd }}$ edition. Boston, MA: PWSKent Publishing Company.

2. Dunning, J.H. (1997). Micro and macro organizational aspects on MNE and MNE activity. International Business: an emerging vision, Columbia, SC: University of South Columbia Press.

3. Hofstede, G. (1980). Culture's Consequences: International differences in work-related values. Beverly Hills, CA: Sage.

4. Hofstede, G. (1983). The cultural relativity of organizational practices and theories. Journal of International Business Studies, (Fall), 75-89.

5. Hofstede, G. (1984). Culture's Consequences: International differences in work-related values (Abridged Edition), Beverly Hills, CA: Sage Publications.

6. Hofstede, G. (1994). Cultures and organizations: Intercultural cooperation and its importance for survival. Hammersmith: Harper Collins Publishers.

7. Hofstede, G. (1997). Cultures and Organizations: Software of the Mind, New York, McGraw Hill.

8. INEGI, (2004). Instituto Nacional de Estatisticas, Geografia e Informatica, http://www.inegi.gob.mx.

9. Nieves, R. and Mujtaba, B. G. (2006). Cultural Values, Engineering Culture, Technology, and International Joint Ventures. Chapter in Privatization and Market-Based Leadership in Developing Economies: Capacity Building in Afghanistan. Pages 271-290. Llumina, Coral Springs, U.S.A.

10. Schwartz, S.H. (1990). Individualism-collectivism: Critique and proposed refinements. Journal of CrossCultural Psychology, 21, 139-157.

11. Schwartz, S.H. (1992). Universal in the content of and structure of values: Theoretical advances and empirical tests in 20 countries. In M.P. Zanna (Ed.), Advances in experimental social psychology (Vol. 24, pp. 1-65). San Diego, CA: Academic Press.

12. Schwartz, S.H. (1996). Value priorities and behavior: Applying a theory of integrated value systems. In C. Seligman, J.M. Olson, and M.P. Zanna (Eds.), The psychology of values: The Ontario symposium (Vol. 8, 124). Mahwah, NJ: Erlbaum.

13. Schwartz, S.H. (1999). A theory of cultural values and some implications for work. Applied Psychology: An International Review, 84(1), 23-47.

14. Schwartz, S.H. and Bilsky, W. (1987). Toward a universal psychological structure of human values. Journal of Personality and Social Psychology, 53, 550-562.

15. Schwartz, S.H. and Bilsky, W. (1990). Toward a theory of the universal content and structure of values: Extensions and cross-cultural replications. Journal of Personality and Social Psychology, 58, 878-891.

16. Schwartz, S.H. and Ros, M. (1995). Values in the West: A theoretical and empirical challenge to the individualism-collectivism cultural dimension. World Psychology, 1, 99-122.

17. Schwartz, S.H. and Sagiv, L. (2000). National cultures: Implications for organizational structure and behavior. In N.N. Ashkanasy, C. Wilderom, \& M.F. Peterson (Eds.), The handbook of organizational culture and climate, 417-436, Newbury Park, CA: Sage.

18. Secretaria de Economia, (2005). Direccion General de Inversion Extranjera, www.economia.gob.mx. 


\section{NOTES}

